\title{
Evaluación de la nisina como sustancia inactivadora de Bacillus licheniformis en el extracto líquido de café
}

\author{
Evaluation of the nisin as inactivator substance of Bacillus \\ licheniformis to coffee liquid extract
}

\author{
Leidy Sierra L, ${ }^{1 *}$ M.Sc, Olga Montoya C, ${ }^{2}$ M.Sc, Héctor J. Ciro-V, ${ }^{3}$ Ph.D.
}

${ }^{1}$ Universidad Nacional de Colombia. Sede Medellín. ${ }^{2}$ Universidad Nacional de Colombia. Facultad de Ciencias. Sede Medellín. ${ }^{3}$ Universidad Nacional de Colombia. Departamento de Ingeniería Agrícola y de Alimentos. Sede Medellín. *Correspondencia: Imsierr0@gmail.com

Recibido: Julio de 2012; Aceptado: Marzo de 2013.

\section{RESUMEN}

Objetivo. Evaluar el efecto de la nisina en la inactivación de Bacillus licheniformis en el extracto líquido de café. Materiales y métodos. Se evaluó la acción de la nisina sobre Bacillus licheniformis en extractos líquidos de café variando su concentración, tiempo de incubación, concentración de solidos solubles (grados Brix) y la concentración bacteriana contaminante. Resultados. Se observó que la concentración de nisina, para obtener un efecto inhibitorio del $55 \%$, sin alterar las propiedades fisicoquímicas y sensoriales del producto, es $500 \mathrm{UI} / \mathrm{ml}$ que corresponden a $12.5 \mathrm{mg} / \mathrm{L}$. Además, se determinó que la concentración de nisina $1000 \mathrm{UI} / \mathrm{ml}$ puede actuar satisfactoriamente en poblaciones bacterianas menores de $5 \times 10^{4} \mathrm{UFC} / \mathrm{ml}$ en un período de 48 horas. Con relación al efecto de concentración de sólidos solubles en la inactivación del microorganismo, no se encontraron diferencias significativas para un rango entre 15 y $45^{\circ}$ Brix. Conclusiones. A partir de este estudio se puede concluir que la nisina puede ser usada como preservante del extracto de líquido de café sin afectar sensorialmente el producto, teniendo en cuenta la concentración bacteriana contaminante y el tiempo de incubación.

Palabras clave: Bacillus, café, inactivación, nisina (Fuente: $C A B$ ).

\begin{abstract}
Objetive. To evaluate the effect of nisin on the inactivation of Bacillus licheniformis to coffee liquid extract. Materials and methods. The action of nisin on Bacillus licheniformis into liquid coffee extracts was evaluated by varying its concentration, incubation time, concentration of soluble solids ( ${ }^{\circ} \mathrm{Brix}$ ) and bacterial contaminant concentration. Results. The results indicated that the concentration of nisin to achieve the inhibitory effect without affecting the physicochemical and sensory properties of the product is $500 \mathrm{IU} / \mathrm{ml}$ corresponding to $12.5 \mathrm{mg} / \mathrm{L}$. Additionally, High levels of nisin $1000 \mathrm{IU} /$ $\mathrm{ml}$ can act successfully in bacterial populations lower than $5 \times 10^{4} \mathrm{CFU} / \mathrm{ml}$ over a period of 48 hours. Furthermore, the concentration of soluble solids did not show a statistically significant effect for values from 15 to $45^{\circ}$ Brix. Conclusions. From this study it can be concluded that nisin may be used as a preservative in liquid coffee extract without sensorially affecting the product, taking into account the bacterial contaminant concentration and incubation time.
\end{abstract}

Key words: Bacillus, coffee, inactivation, nisin (Source: $C A B$ ). 


\section{INTRODUCCIÓN}

En el sector de los alimentos, el crecimiento económico y la globalización de los mercados han propiciado un ambiente más exigente y competitivo. Lo anterior, se traduce en un mayor compromiso de las industrias alimentarias modernas para garantizar la permanencia de sus productos en el mercado, dado que frecuentemente surgen nuevos productos y mejores tecnologías para su desarrollo.

Así, los entes reguladores de la inocuidad alimentaria establecen una normatividad más exigente para garantizar que estas nuevas alternativas no terminen afectando de manera directa o indirecta la salud humana. Por lo tanto, en el mundo actual de la industria de alimentos uno de los retos más importantes es poder garantizar la inocuidad de los productos asegurando su estabilidad (1).

Los microorganismos del género Bacillus están ampliamente distribuidos en el medio ambiente, y en diversos productos agroalimentarios actúan como agentes patógenos de alimentos ( $B$. cereus) o generadores de putrefacción ( $B$. coagulans, $B$. licheniformis, $B$. subtilis) y formando endosporas resistentes a agentes físicos o químicos utilizados para la conservación de alimentos (2-7).

La nisina es la única bacteriocina que ha sido aprobado por la Organización Mundial de la Salud (OMS), para ser utilizada como conservante en la industria alimentaria; molecularmente es un péptido de 34 aminoácidos con un peso molecular inferior a $5 \mathrm{kDa}(8)$, producida por algunas cepas de Lactococcus lactis, siendo efectiva en el control del crecimiento de los microorganismos formadores de esporas como Bacillus y Clostridium; aunque, también actúa sobre Listeria monocytogenes, Staphylococcus y muchas especies de bacterias ácido lácticas (9). Una amplia descripción de la acción a nivel molecular es referenciada (10).

El extracto líquido de café es el producto resultante del proceso en el cual se hace pasar agua caliente sobre un lecho fijo de café tostado y molido (generalmente a presión y alta temperatura), con el fin de extraer los sólidos y los componentes aromáticos del grano; el licor es utilizado como ingrediente para obtener preparaciones de diferentes alimentos como helados, yogurt, pasteles, bebidas de café entre otros, por lo que no deben contener esporas después de la producción $(11,12)$. Las esporas podrían germinar en los productos elaborados con concentrado de café y al no ser sometidos a un tratamiento posterior de desinfección durante el almacenamiento, el producto se podría recontaminar (12).

Dado que el péptido (nisina) es aceptado como un bioconservante de los alimentos debido a sus propiedades antibacterianas, a su impacto mínimo con relación a los cambios a las propiedades organolépticas de los alimentos $(13,14)$ y a que desde el punto de vista del consumo humano las enzimas digestivas pueden degradarla, el objetivo de esta investigación fue determinar las condiciones óptimas del uso de la nisina en el extracto de café líquido, garantizando la calidad microbiológica y sensorial del producto, con fines de su comercialización internacional.

\section{MATERIALES Y MÉTODOS}

Localización. El trabajo de investigación fue realizado en los laboratorios de Microbiología Industrial y Bioconversiones de la Universidad Nacional de Colombia, Sede Medellín.

Preparación de la muestra. La nisina (1000 UI/ $\mathrm{ml} \mathrm{a} 100 \mathrm{UI} / \mathrm{ml}$ ) se adicionó al extracto líquido de café disuelta en una solución $\mathrm{HCl}(0.02 \mathrm{M})$ y $0.75 \%(\mathrm{p} / \mathrm{v})$ de $\mathrm{NaCl}(15)$. Se procedió a inocular el microorganismo Bacillus licheniformis en tubos conteniendo extracto de café con la bacteriocina, se incubó a $37^{\circ} \mathrm{C}$ y $180 \mathrm{rpm}$ por 24 horas. Cada dos horas, se realizó el recuento de colonias en medio sólido (agar nutritivo).

Actividad antibacteriana. Por medio del antibiograma en medio líquido se evaluó la concentración de nisina (16). Además, se determinó el efecto inhibitorio de la nisina en extractos de café con diferente concentración de solidos solubles (medidos en ${ }^{\circ}$ Brix) e inóculo inicial. Los tiempos de incubación fueron 2, 24 y 48 horas para diferentes concentraciones de inóculo.

En un alimento la concentración máxima admitida de nisina es $125 \mathrm{mg} / \mathrm{kg}$, lo cual corresponde a $5000 \mathrm{UI} / \mathrm{ml}$ (17); por lo tanto, se evaluaron las concentraciones del péptido a 1000, 500, 400, 300,200 y $100 \mathrm{UI} / \mathrm{ml}$.

Obtenidas las condiciones en las cuales se observa el efecto inhibitorio se verificó el efecto de la nisina en las propiedades sensoriales del extracto líquido de café usando la prueba triangular, para la cual se tenían 10 jueces a los que se les solicitó identificar la bebida con sabor diferente de las 3 suministradas (18). Adicionalmente, se determinaron las características fisicoquímicas 
del extracto tales como el $\mathrm{pH}$ y la acidez, luego de adicionar la bacteriocina.

\section{RESULTADOS}

Acción de la nisina sobre Bacillus licheniformis inoculando en extractos de café con diferente concentración de sólidos solubles ( ${ }^{\circ}$ Brix). Se evaluaron dos concentraciones ( 15 y 45 'Brix) del extracto de café, valores que fueron seleccionados porque a $45^{\circ} \mathrm{Brix}$ es el valor promedio del producto final y $15^{\circ}$ Brix debido a que gran parte del proceso de producción el extracto contiene esta concentración.

La figura 1 muestra los resultados del uso de nisina a $1000 \mathrm{UI} / \mathrm{ml}$ sobre Bacillus licheniformis inoculado a la concentración inicial $6 \times 10^{6} \mathrm{UFC} / \mathrm{ml}$ en los extractos de café a 15 y $45^{\circ}$ Brix. Después de un período de 24 horas a $37^{\circ} \mathrm{C}$, se determinó que no hubo diferencias significativas, en los recuentos de Bacillus licheniformis, entre las dos concentraciones $(p>0.05)$.

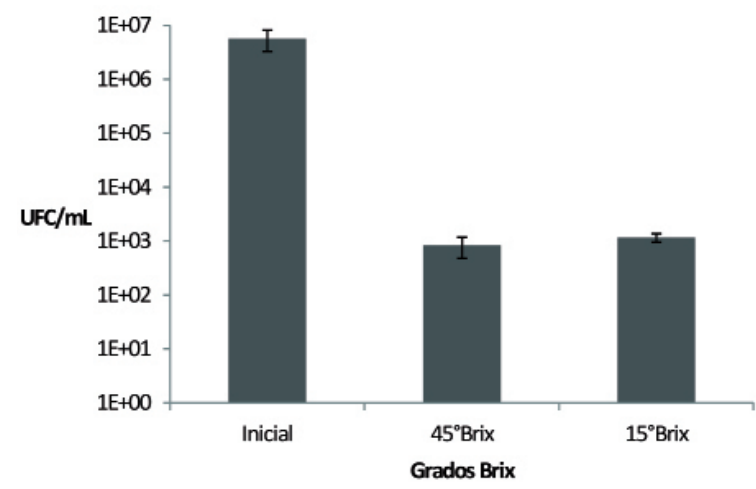

Figura 1. Evaluación de la acción de la nisina (1000 UI/ $\mathrm{ml}$ ) sobre Bacillus licheniformis inoculado en extractos de café con diferentes grados Brix.

Efecto de la concentración de la nisina sobre la inactivación de Bacillus licheniformis. En la figura 2 se observa el crecimiento del microorganismo con nisina para concentraciones de 0 (control) y $1000 \mathrm{UI} / \mathrm{ml}$.

La figura 2 muestra un efecto acelerado de decrecimiento de la carga microbiana en el cual se logra obtener una reducción de dos unidades logarítmicas para un tiempo de 2 horas y luego se observa un efecto bacteriostático.

La figura 3 muestra el efecto de la nisina sobre Bacillus licheniformis cuando la concentración de la bacteriocina disminuye a 500 y $750 \mathrm{UI} / \mathrm{ml}$, donde se observa para estas dos concentraciones de nisina que el efecto predominante es bacteriostático.

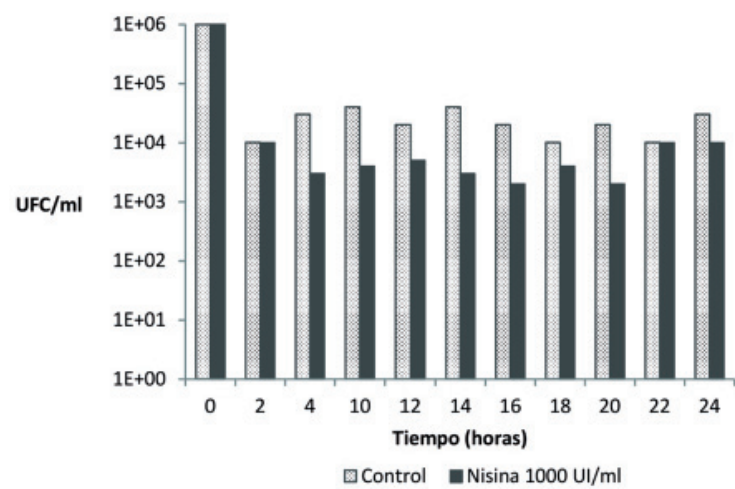

Figura 2. Cinética de Bacillus licheniformis creciendo en un extracto de café a $15^{\circ}$ Brix conteniendo nisina a concentraciones de 0 (control) y $1000 \mathrm{UI} / \mathrm{ml}$ durante 24 horas.

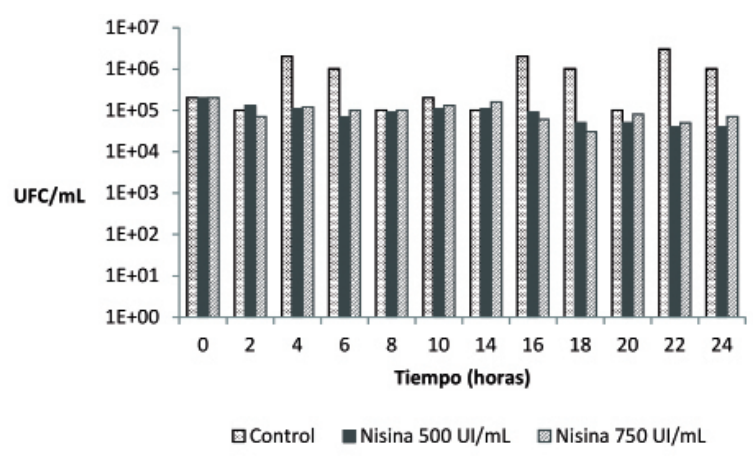

Figura 3. Cinética de Bacillus licheniformis creciendo en el extracto de café a $15^{\circ}$ Brix con 500 y $750 \mathrm{UI} / \mathrm{ml}$ de nisina durante 24 horas.

Con los resultados dados en las figuras 4 y 5 , donde están evaluados los efectos de la nisina a las concentraciones de $400 \mathrm{UI} / \mathrm{ml}$ hasta $100 \mathrm{UI} /$ $\mathrm{ml}$, se puede deducir que no hay efecto inhibitorio significativo.

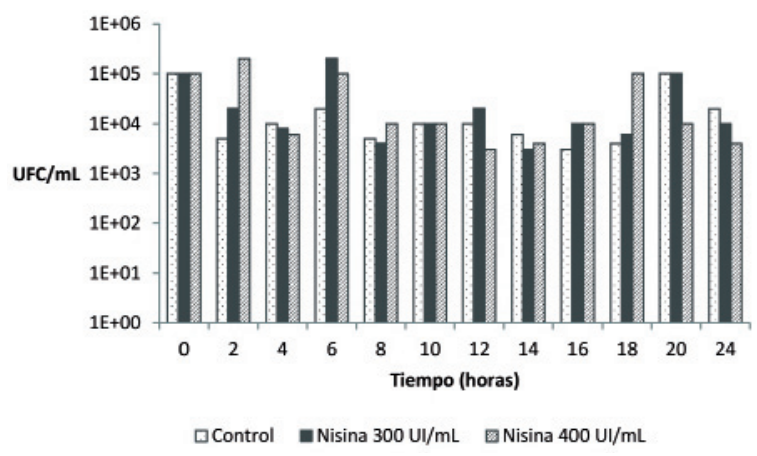

Figura 4. Cinética de Bacillus licheniformis creciendo en el extracto de café a $15^{\circ}$ Brix con 400 y $300 \mathrm{UI} / \mathrm{ml}$ de nisina durante 24 horas. 


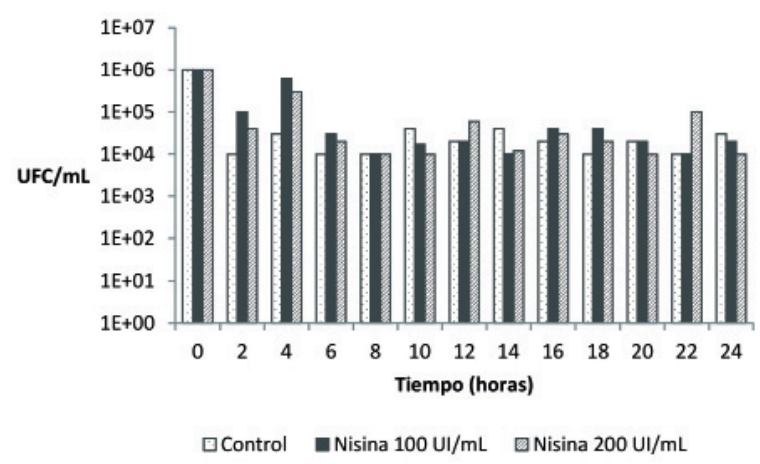

Figura 5. Cinética de Bacillus licheniformis creciendo en el extracto de café a $15^{\circ}$ Brix con 100 y $200 \mathrm{UI} / \mathrm{ml}$ de nisina durante 24 horas.

Acción de la nisina sobre el crecimiento de Bacillus licheniformis inoculado a diferentes niveles de concentración inicial. Para encontrar la concentración de inóculo en la cual se reduce al máximo la carga microbiana por el efecto de la nisina a $1000 \mathrm{UI} / \mathrm{ml}$, se utilizó el extracto de café a $15^{\circ}$ Brix y se evaluaron varios niveles de concentración inicial de inóculo. Los resultados se presentan en la figura 6 .

De la figura 6 se puede inferir que tanto el café con nisina como el café sin ella, tienen un efecto inhibitorio, obteniendo porcentajes de disminución de la población microbiana del 95 y $90 \%$ respectivamente para cuando la concentración inicial de inóculo fue de $4 \times 10^{3}$ $\mathrm{UFC} / \mathrm{ml}$.

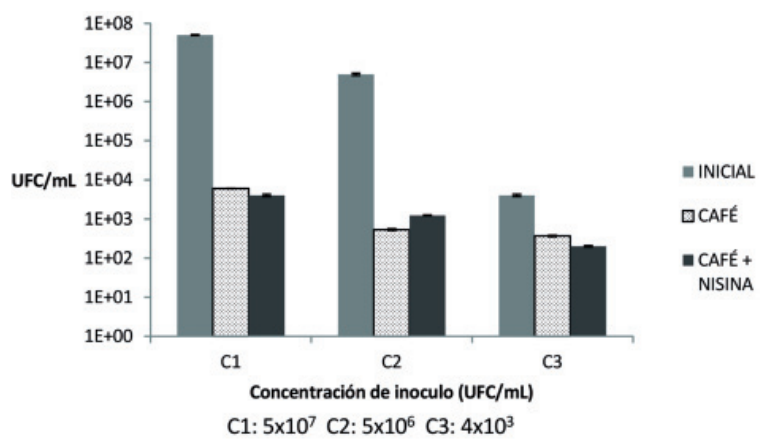

Figura 6. Conteo microbiano luego de 24 horas de incubación, en un extracto de café de 15 'Brix conteniendo nisina (0 y $1000 \mathrm{UI} / \mathrm{ml}$ ) e inoculando con Bacillus licheniformis a diferentes niveles de concentración.

Acción de la nisina sobre el crecimiento de Bacillus licheniformis evaluado a diferentes tiempos de incubación. En los experimentos realizados a diferentes concentraciones del inóculo, usando $1000 \mathrm{UI} / \mathrm{ml}$ de nisina y como medio de cultivo el extracto de café a $15^{\circ} \mathrm{Brix}$, se evaluó el efecto antimicrobial de la bacteriocina en un tiempo de incubación de 2, 24 y 48 horas. Los resultados mostraron que para una concentración inicial microbiana de $10^{7} \mathrm{UFC} / \mathrm{ml}$, el efecto de la nisina se da principalmente a las 2 horas y posteriormente permanece constante (Figura 7a).

En la figura $7 b$ se observa que cuando la concentración bacteriana inicial es de $\left(5 \times 10^{4}\right.$ UFC/ $\mathrm{ml})$, la acción de la nisina es más contundente, porque se logra disminuir la población de Bacillus licheniformis hasta $3 \mathrm{UFC} / \mathrm{ml}$ a las 48 horas, mientras que en el medio con sólo café el recuento es en promedio $30 \mathrm{UFC} / \mathrm{ml}$.
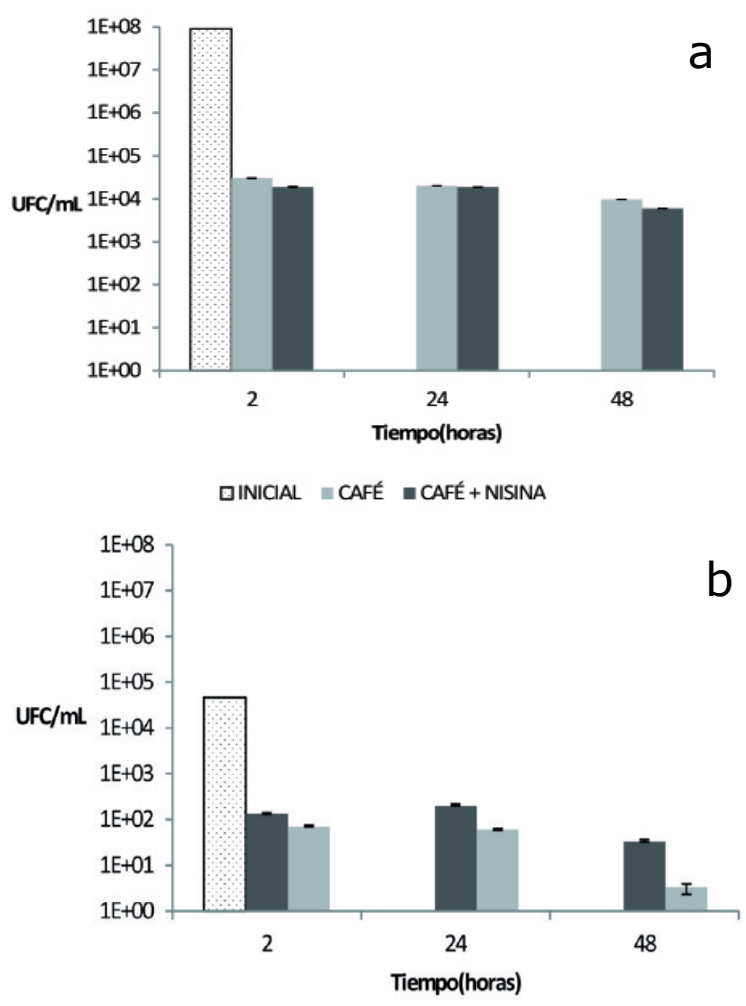

口INICAL $=$ CAFÉ $=$ CAFÉ + NISINA

Figura 7. Acción bactericida de la nisina sobre la concentración de inóculo a 2, 24 y 48 horas de incubación: $1 \times 10^{7} \mathrm{UFC} / \mathrm{ml}$ (a) y $5 \times 10^{4}$ $\mathrm{UFC} / \mathrm{ml}$ (b).

Prueba sensorial y los análisis fisicoquímico. De acuerdo con los resultados anteriores, las concentraciones de nisina con las que se obtuvo inhibición fueron 500 y $1000 \mathrm{UI} / \mathrm{ml}$. Así, se evaluaron los efectos de la adición de la nisina en las propiedades sensoriales y fisicoquímicas del extracto de café ( $\mathrm{pH}$ y acidez) con concentraciones de nisina de 0,1000 y 500 $\mathrm{UI} / \mathrm{ml}$. Los resultados se presentan en la figura 8 .

De la figura 8, se observa que el tratamiento con nisina no afecta las propiedades fisicoquímicas del extracto de café ( $\mathrm{pH}$ y acidez) ya que es estadísticamente igual al control $(p>0.05)$. 


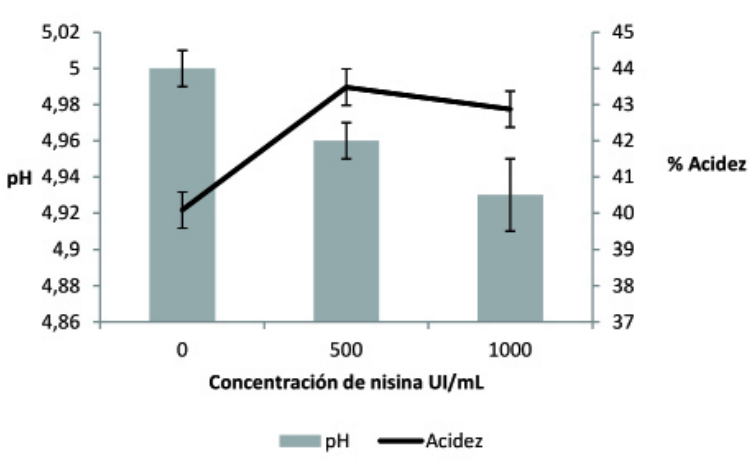

Figura 8. Efecto de la adición de nisina en el pH y el porcentaje de acidez del extracto de café a las concentraciones de 0, 500 y $1000 \mathrm{UI} /$ $\mathrm{ml}$.

A partir de un análisis de varianza de la prueba triangular se observó que hay diferencias significativas $(p<0.05)$ entre el control y el tratamiento $(1000 \mathrm{UI} / \mathrm{ml})$, mientras que para concentración de nisina (500 UI/ml) no hay diferencias significativas $(p>0.05)$.

\section{DISCUSIÓN}

La acción de la nisina no depende de la concentración de sólidos solubles, ya que si la viscosidad se incrementa debido al aumento de fracción másica del café (19), esto se convierte en un factor limitante para la acción de la nisina, aunque se esperaba que a medida que aumentara la concentración de solidos solubles del café la inhibición fuera mayor.

Por otro lado, el $\mathrm{pH}$ es fundamental para la acción de la nisina siendo mejor a $\mathrm{pH}$ bajos (20). Para las concentraciones de 45 y $15^{\circ}$ Brix los valores de $\mathrm{pH}$ fueron respectivamente de $5.06 \pm 0.03$ y $5.00 \pm 0.03$, con lo cual se podria inferir que este factor no es determinante para la acción inhibitoria de la nisina y por lo tanto, no se observa una diferencia significativa en la inhibición de la bacteria de interes.

La concentración de nisina está relacionada con el efecto inhibitorio ya que para concentraciones de $1000 \mathrm{UI} / \mathrm{ml}$, se observa que la población bacteriana disminuye, mientras que para valores entre 750 y $500 \mathrm{UI} / \mathrm{ml}$ el efecto que se observó es bacteriostatico y en la medida en que se disminuye la concentración de nisina, el efecto inhibitorio desaparece. Los resultados obtenidos coinciden con Chatterjee et al (21), ya que se logró demostrar que la acción de la nisina frente a las células vegetativas de Bacillus puede ser bactericida o bacteriostática dependiendo de la concentración de la misma.
El criterio microbiológico para mesófilos en el extracto de café debe ser menor a $100 \mathrm{UFC} / \mathrm{ml}$ (22). Así, con respecto a la concentración de inóculo inicial que es sometida al tratamiento con nisina, se encontró que para obtener valores de UFC/ml menores a 100, la concentración inicial de inóculo debe ser menor de 4x103 UFC/ml, ya que con los valores superiores no se logra que la población bacteriana sea menor de $100 \mathrm{UFC} / \mathrm{ml}$, por lo cual debería agregarse nisina para obtener una inactivación mayor de la bacteria.

El café tiene propiedades antimicrobiales sobre algunos microorganismos tanto Gram negativos como Gram positivos, aunque, la sensibilidad disminuye con este último grupo (10). El peróxido presente en el café es el principal responsable de tal inhibición (23). Adicionalmente, la disminución de bacterias se debe a compuestos como ácido 5-cafeoilquinico, trigonelina y ácido cafeico (24).

Por otro lado, si se mezcla el extracto de café $15^{\circ}$ Brix con nisina a la concentración de 1000 $\mathrm{UI} / \mathrm{ml}$ se observa el efecto inhibitorio. La figura 6 muestra que la acción de la nisina es dependiente de la concentración de bacterias, ya que entre mayor sea la población microbiana se requiere más concentración de nisina para obtener valores finales menores a $100 \mathrm{UFC} / \mathrm{ml}$ (3).

El tiempo de incubación también mostró ser crítico para la eficiencia de la bacteriocina, ya que cuando se tienen concentraciones iniciales de inóculo del orden de $10^{6}$ y $10^{7} \mathrm{UFC} / \mathrm{ml}$, aumentar el tiempo de incubación no hace que la disminución de la carga bacteriana sea mayor, así, podría considerarse que en estos niveles no es justificado el uso de la nisina. Sin embargo, en la figura 7, se puede apreciar que el tiempo de incubación resulta importante para alcanzar los valores bajos (3 UFC/ml).

Con relación al nivel de concentración, se observó que cuando la concentración bacteriana inicial es de $5 \times 10^{4} \mathrm{UFC} / \mathrm{ml}$, la acción de la nisina es más contundente, porque se logran disminuir la población de Bacillus licheniformis hasta 3 UFC/ $\mathrm{ml}$ a las 48 horas, mientras que en el medio con sólo extracto de café, el recuento es 30 UFC/ $\mathrm{ml}$. Esto demuestra la efectividad de la nisina en la disminución del crecimiento de Bacillus licheniformis. De la misma manera, se muestra que para un período de 24 horas, el recuento de bacterias con sólo extracto de café es de $2 \times 10^{2}$ $\mathrm{UFC} / \mathrm{ml}$, mientras que con la adición de la nisina se obtienen $60 \mathrm{UFC} / \mathrm{ml}$, con lo cual se cumpliría la norma de calidad de COLCAFÉ S.A.S., (<100 $\mathrm{UFC} / \mathrm{ml}$ ) para este producto que al ser tipo exportación tiene requerimientos más altos. 
Dado que las pruebas sensoriales y fisicoquímicas no mostraron diferencias significativas con el control, cuando se usó la concentración de $500 \mathrm{UI} / \mathrm{ml}$, se concluye que esta concentración es la indicada ya que su efecto es bacteriostático y protege las propiedades sensoriales del café, que es una de las características de mayor interés en la comercialización de este producto.

A partir de este estudio se puede inferir que la nisina podría ser usada como preservante del extracto de líquido de café, ya que contribuye a disminuir o mantener constante la población microbiana del microorganismo de mayor termo-resistencia presente en el producto. La adición de la nisina como preservante en el extracto líquido de café depende de la concentración inicial de bacterias, y la concentración de la nisina, más no de la concentración de sólidos solubles (expresados en grados ${ }^{\circ}$ Brix del producto).
Las condiciones en las cuales debe ser usada la nisina en el extracto líquido de café es a la concentración de $500 \mathrm{UI} / \mathrm{ml}$ y tiempo de incubación 48 horas cuando la concentración inicial de Bacillus licheniformis es $5 \times 10^{4} \mathrm{UFC} /$ $\mathrm{ml}$, valor cercano a los encontrados en el extracto de café contaminado luego de su comercialización, para obtener una reducción de 4 ciclos logarítmicos.

El extracto líquido de café tiene propiedades antimicrobiales contra Bacillus licheniformis, permitiendo disminuir la población inicial de bacterias por cierto tiempo y posteriormente genera la esporulación del microorganismo de interés

\section{Agradecimientos}

A los Laboratorios de Microbiología industrial y Bioconversiones de la Universidad Nacional de Colombia y a la empresa Colcafé S.A.S.

\section{REFERENCIAS}

1. Galvez A, Lopez R, Abriouel H, Valdivia $\mathrm{E}$, Omar N. Application of bacteriocins in the control of foodborne pathogenic and spoilage bacteria. Crit Rev Biotechnol 2008; 28(2): 125-152.

2. Carlin F, Guinebretiere $\mathrm{MH}$, Choma C, Pasqualini R, Braconnier A, Nguyen-The C. Spore forming Bacteria in commercial cooked, pasteurized and chilled vegetable purees. Food Microbiol 2000; 17(2):153-165.

3. Delves-Broughton J. Nisin as a food preservative. Food Australia 2005; 57(12):527-525.

4. Faustino A, Juncioni de Arauz L, Gava P, Vessoni T. Nisin biotechnological production and application: a review. Tren in Food Sci Technol 2009; 20:146-154.

5. Jeevaratnam K, Jamuna M, Bawa A. Biological preservation of foods- Bacteriocins of lactic acid bacteria. Indian J Biotechnol. 2005; $4: 446-454$
6. Mansour M, Millière J-B. An inhibitory synergistic effect of a nisin-monolaurin combination on Bacillus sp. vegetative cells in milk. Food Microbiol 2001; 18(1):87-94.

7. Scurrah J, Robertson E, Craven M, Pearce E, Szabo A. Inactivation of Bacillus spores in reconstituted skim milk by combined high pressure and heat treatment. J Appl Microbiol 2006; 10:172-180.

8. McAuliffe O, Ross R, Hill C. Lantibiotics: structure, biosynthesis and mode of action. FEMS Microbiol Rev 2001; 25(3):285-308.

9. Bouttefroy A, Mansour M, Linder M, Milliere J. Inhibitory combinations of nisin, sodUIm chloride, and $\mathrm{pH}$ on Listeria monocytogenes ATCC 15313 in broth by an experimental design approach. Int J Food Microbiol 2000; 54:109-115.

10. Murthy PS, Manonmani HK. Physico-chemical antioxidant and antimicrobial properties of Indian monsooned coffee. Eur Food Res Technol 2009; 229(4):645-650. 
11. Giraldo C. Diseño de un equipo que evite el arrastre de extracto liquido de café para acoplarlo a un evaporador de placas. [Tesis]. Bogotá: Tesis Universidad Pontificia Bolivariana; 2002.

12. Manzano M, GUIsto C, Iacumin L, Cantoni C, Comi G. A molecular method to detect Bacillus cereus from a coffee concentrate sample used in industrial preparations. J Appl Microbiol 2003; 95(6):1361-1366.

13. Guerra N, Torrado A, Lopez C, Fajardo P, Pastrana L. Dynamic mathematical models to describe the growth and nisin production by Lactococcus lactis subsp. lactis CECT 539 in both batch and re-alkalized fed-batch cultures. J Food Eng 2007; 82(2):103-113.

14. Tiwari $B K$, Valdramidis $V P, O^{\prime}$ Donnell $C P$, Muthukumarappan K, Bourke $\mathrm{P}$, Cullen PJ. Application of natural antimicrobials for food preservation. J Agric Food Chem 2009; 57(14):5987-6000.

15. Yoon J, Bajpai V, Kang S, Synergistic effect of nisin and cone essential oil of Metasequoia glyptostroboides Miki ex Hu against Listeria monocytogenes in milk samples. Food Chem Toxicol 2011; 49(1):109-140.

16. Reller LB, Weinstein MP, Editors S, Jorgensen $\mathrm{JH}$, Ferraro MJ. Antimicrobial susceptibility testing: A Review of general principles and contemporary practices. Clin Infect Dis 2009; 7750:1749-1755.

17. Ministerio de Salud. Resolución 4125 anexo 4.61. Conservantes usados en alimentos. Bogotá, Colombia: Ministerio de Salud; 1991.
18. Instituto Colombiano de Normas Técnicas (ICONTEC). Norma Técnica Colombiana NTC 2681: Análisis sensorial, metodología prueba triangular. Bogotá, Colombia: ICONTEC; 2006.

19. Sobolik V, Zitný R, Tovcigreeko V, Delgado M, Allaf K. Viscosity and electrical conductivity of concentrated solutions of soluble coffee. J Food Eng 2002; 51(2):93-98.

20. Herman C, Maguna F, Garro O, Castro E. Effect of temperature, $\mathrm{pH}$ and $\mathrm{NaCl}$ on nisin activity against Lactobacillus fructivorans. ] Argentine Chem Soc 2009; 97(2): 11-18.

21. Chatterjee C, Paul M, Xie L, Van der Donk W. Review biosynthesis and mode of action of lantibiotics. Chem Rev 2005; 105 (2): 633-684.

22. Instituto Colombiano de Normas Técnicas (ICONTEC). Norma Técnica Colombiana NTC 4675: Extractos solubles de café. Bogotá, Colombia: ICONTEC; 1999.

23. Mueller $U$, Sauer $T$, Weigel I, Pichner $R$, Pischetsrieder $M$. Identification of $\mathrm{H}_{2} \mathrm{O}_{2}$ as a major antimicrobial component in coffee. Food Funct 2011; 2:265-272.

24. Antonio G, Moraes RS, Perrone D, Maia LC, Santos RN, Farah A. Species, roasting degree and decaffeination influence the antibacterial activity of coffee against Streptococcus mutans. Food Chem 2010; 118:782-788. 